\title{
Projecting global and regional outlooks for planted forests under the shared socio-economic pathways
}

\author{
Jaana Korhonen ${ }^{1}$ D $\cdot$ Prakash Nepal $^{2}$ - Jeffrey P. Prestemon ${ }^{3} \cdot$ Frederick W. Cubbage $^{4}$
}

Received: 9 September 2019 / Accepted: 28 April 2020 / Published online: 9 May 2020

(c) The Author(s) 2020

\begin{abstract}
There is rising global interest in growing more trees in order to meet growing population, climate change, and wood energy needs. Using recently published data on planted forests by country, we estimated relationships between per capita income and planted forest area that are useful for understanding prospective planted forest area futures through 2100 under various United Nations Intergovernmental Panel on Climate Change-inspired Shared Socio-economic Pathways (SSPs). Under all SSPs, projections indicate increasing global planted forest area trends for the next three to four decades and declining trends thereafter, commensurate with the quadratic functions employed. Our projections indicate somewhat less total future planted forest area than prior linear forecasts. Compared to 293 million ha (Mha) of planted forests globally in 2015, SSP5 (a vision of a wealthier world) projects the largest increase (to 334 Mha, a $14 \%$ gain) by 2055, followed by SSP2 (a continuation of historical socio-economic trends, to 327 Mha, or an 11\% gain), and SSP3 (a vision of a poorer world, to 319 Mha, a $9 \%$ gain). The projected trends for major world regions differ from global trends, consistent with differing socio-economic development trajectories in those regions. Our projections based on empirical FAO data for the past 25 years, as well as those by other researchers, suggest that achieving the much more ambitious global planted forest targets proposed recently will require exceptional forest land and investment supply shifts.
\end{abstract}

Keywords Planted forests · Shared socio-economic pathways · Forest sector policy $\cdot$ Panel data

\section{Introduction}

Planted forests provide many benefits including traditional wood production, employment and economic development, and have been identified as a key means to ameliorate climate change in the short to medium term. According to the recently published report by the Intergovernmental Panel on Climate Change (IPCC 2019), changes in land conditions, either from land-use or climate change, affect global and regional climate.

Jaana Korhonen

jaana.e.korhonen@helsinki.fi

Extended author information available on the last page of the article 
Climate change could affect the area of productive land available for agriculture and other growing, independent of population and economic growth related pressures (e.g., Zhang and Cai 2011; King et al. 2018). At the same time, others (e.g., Lambin and Meyfroidt 2011) point to the effects of economic growth at producing conditions of rising land scarcity overall. The IPCC (2019) summarizes, with a high level of scientific confidence, that "changes in forest cover, for example from afforestation, reforestation and deforestation, directly affect regional surface temperature through exchanges of water and energy", anticipating that the potential role of forests in mitigating the effects of climate change will only increase.

Globally, there are a number of multi-national forest restoration and creation initiatives, including, among others, the New York Declaration on Forests (NYDF), which was first endorsed at the United Nations climate summit in 2014 (UN 2014), and the Bonn Challenge, which is a platform to achieve multiple restoration targets under one initiative (IUCN 2015). For example, the African Forest Landscape Restoration Initiative (AFR100) aims to restore 100 million hectares by 2030 . Similarly, The Initiative $20 \times 20$ plans to bring more than 20 million hectares of degraded land in Latin America and the Caribbean into restoration by 2020. Likewise, signatory nations of the Asia-Pacific Economic Cooperation (APEC) set a goal for 2020 to increase forest cover by 20 million hectares, which is almost met by today. Furthermore, for example, The World Wide Fund for Nature's Living Forests Report projects that around 250 million hectares of new planted forests would be established globally between 2010 and 2050 under a scenario involving expanded wood use in the bioenergy sector (WWF 2012).

Alongside nongovernmental organizations' actions and initiatives, several individual countries and states have established efforts to promote the expansion of planted forests or strengthen the protection of existing forests. Most significantly, participants at the World Economic Forum in 2020 (WEF 2020; 1t.org 2020) announced an initiative to grow, restore, and conserve one trillion trees around the world. Perhaps not all of these of these would be new planted forests, but if so, it would amount to an increase of one billion ha of forests-expanding global forest area by $25 \%$ - at an approximate stocking rate of 1000 trees per ha. More immediate plans to address climate change include emerge from the State of California, whose government now allows forestland owners to receive carbon credits for increasing carbon sequestration in their forests (Popkin 2019). Finally, the European Union is moving toward allowing countries to include forest planting in their climate change mitigation practices (Popkin 2019).

Changes in global forest areas can be particularly attributed to demographic and economic growth (Sloan and Sayer 2015; Nepal et al. 2019a). Recent overall growth in planted forest area may be linked in part to economic signals from the forest product sector (e.g., higher timber prices), which provide monetary incentives to invest in forestry (Rudel et al. 2005; Nepal et al. 2019b). Payn et al. (2015) reported that official United Nations Food and Agricultural Organization data, largely based on national official statistics from each country spanning roughly the years 1990-2015, reveal an increasing trend in planted forest area (from 167.5 to $277.9 \mathrm{Mha}$ ). The study also found that the most rapid historical expansion of planted forest area was in temperate zones, particularly in East Asia, Europe, North America, and Southern and Southeast Asia. Research that can clarify how changing societies and shifting global economic conditions might affect investment into planted forest is needed to enable accurate assessments of existing and proposed land and forest sector policies. Such analyses could also improve our understanding of how future changes in society could lead to shifts in land uses, ecosystem goods and service provisioning, and the production and trade of forest products. Such new knowledge may also be valuable to 
policymakers who seek to evaluate the scale of the possible consequences and the optimal design of programs aimed at expanding planted forest area.

In this study, we seek to provide insights into the prospective planted forest area futures in various countries, aggregated into major regions and the world, based on actual historical data and statistical analyses, under varying assumed economic and demographic futures. Projections providing such insights are done by, first, estimating the econometric relationship between global planted forest area and income per capita, along with a set of other socio-economic variables identified based on theory and recent empirical analysis. The estimated relationship with income per capita is then used to project future planted forest area under varying economic and demographic futures envisioned under different Shared Socio-economic Pathways (SSPs) (O'Neill et al. 2014, 2017), as discussed in the following sections.

\section{Shared socio-economic pathways (SSPs)}

This study provides topical and novel future projections of planted forest area under three distinct Shared Socio-economic Pathways (SSPs) representing varying world visions that were developed in conjunction with the IPCC Fifth Assessment. The SSPs describe different socio-economic, technological, environmental, and policy futures of the world, with varying degree of challenges for climate change mitigation and adaptation (Table 1). A recent study by Daigneault et al. (2019) builds upon existing SSP foundations by elaborating on the potential implications of SSP-related variables on forest resource management, forest product markets, wood-based bioenergy expansion, and other relevant trends in global forestry. We draw on some of those key assumptions related to plantation forest management under each SSP, as summarized in Table 1.

Compared to other SSPs, SSP1 and SSP5 represent visions of the wealthiest and most equal future worlds with the least population growth (O'Neill et al. 2017). While SSP5 envisions a world that is reliant on fossil-fuels, SSP1 characterizes a more sustainable outlook for the world, emphasizing the de-carbonization of society through low consumption growth and improved energy efficiency. SSP2 represents a world vision that more closely reflects a continuation of recent historical socio-economic trends. In contrast, SSP3 and SSP4, compared to other SSPs, envision poorer and unequal worlds, where SSP4 represents the most unequal world in terms of economic and technological development, investment in human capital and environmental emissions (O'Neill et al. 2017).

Building on the original SSP narratives, Daigneault et al. (2019) make assumptions, for example, regarding technological development, stringency of regulation and rate of deforestation under each SSPs. They summarize that the best planted forest management practices are found in association with SSP1, consistent with high productivity growth, backed by strong regulations to avoid ecological tradeoffs in this pathway. Under SSP2, they imputed a medium rate of productivity growth coupled with a medium levels of regulation, with the net effect of a slow decline in deforestation. Under SSP3, very poor forest productivity growth is anticipated, and very little regulation is assumed to be in place. Under SSP4, the productivity growth and stringency of environmental regulations are unequal in different parts of the world, leading to deforestation in areas without regulation. Lastly, under SSP5, there is rapid productivity growth but, similar to SSP2, a slow decline in deforestation and relatively small increase in natural forest area. The authors do not, however, explicitly evaluate how the various SSPs may lead to distinct trends in planted forest area, which is a specific focus of our analyses. Based on this important question, 


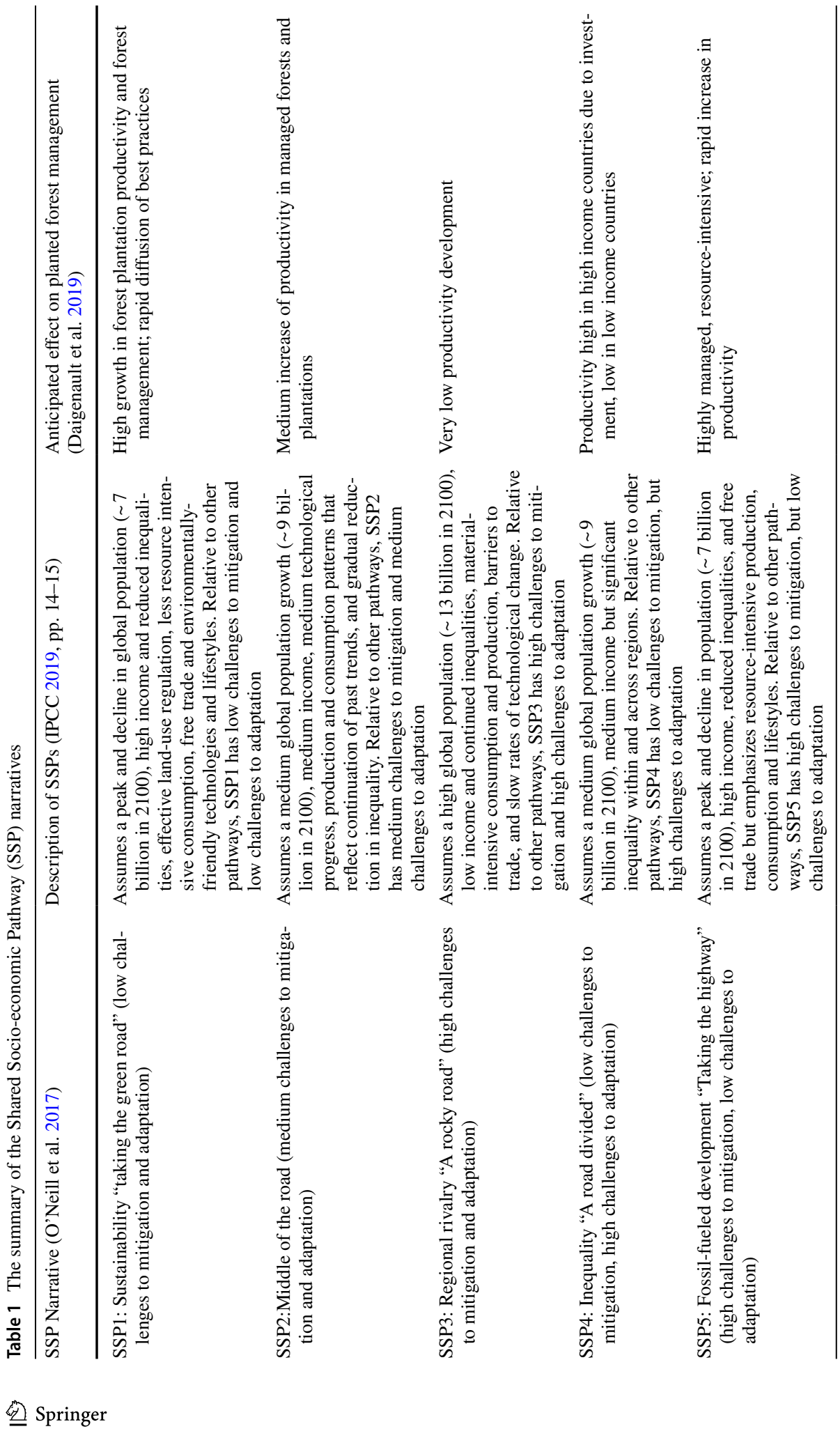


we aim to model the future planted forest area development under quantitative scenarios inspired by the SSP narratives (O'Neill et al. 2017), reflecting the developments also with recent SSP narratives created for forest sector (Daigneault et al. 2019).

\section{Methods}

\section{Empirical approach}

To characterize the relationship between economic development and planted forest area at the global level, we estimated an econometric model of planted forest area with the specification originally presented by Turner et al. (2006). They modeled annual changes in total forest area by country as functions of scale, technique, and composition effects represented by income per capita, rural population density, labor per unit of forest area, capital per unit of forest area, and by the country's openness to trade (see also Antweiler et al. 2001; Cole and Elliott 2003). Although their specification was used to model annual changes in total forest area, we chose the same specification to model planted forest area because it captures the impact of investments designed to intensify forest management, including through tree planting. The inclusion of composition effects captures the situation where a country changes its derived forest product mixes as income rises (e.g., switching to alternative sources of energy from traditional fuelwood). Rural population density can represent the scale of forest use (including planted forests), whereas income per capita and its squared term models the technique effect. Finally, inclusion of a measure of a countries' openness to trade (or trade intensity), interacted with other variables in the model, is designed to represent the influence of the global market on domestic supply of forest products, i.e., the extent to which the relative comparative advantage of a country (e.g., Bonnefoi and Buongiorno 1990) is operational on the domestic forest sector.

Following Turner et al. (2006), the planted forest area model estimated in this study is represented in Eq. 1:

$$
\begin{aligned}
P A_{i t}= & \beta_{0}+\beta_{1}\left(\frac{Y}{N}\right)_{i t}+\beta_{2}\left(\frac{Y}{N}\right)_{i t}^{2}+\beta_{3} U_{i t}+\beta_{4}\left(\frac{L}{A}\right)_{i t}+\beta_{5}\left(\frac{K}{A}\right)_{i t}+\beta_{6}\left(\frac{L}{A}\right)_{i t}\left(\frac{K}{A}\right)_{i t} \\
& +\beta_{7} \emptyset_{i t} I_{i t}+\beta_{8} D_{1}+\beta_{9} D_{2}+\beta_{10} D_{3}+\beta_{11} D_{4}+\beta_{12} D_{5}+\varepsilon_{i t}
\end{aligned}
$$

where $P A_{i t}=$ planted forest area (ha); thus, any changes in planted forest area from period $t-1$ to $t$ are the result of net changes in afforestation during $t-1$ to $t$ (forest area established through planting and/or deliberate seeding); $\beta=$ a vector of parameters containing a constant $\left(\beta_{0}\right)$, coefficients associated with the independent variables $\left(\beta_{1}\right.$ to $\left.\beta_{7}\right)$, and regional dummy variables $\left(\beta_{8}\right.$ to $\left.\beta_{12}\right) ;\left(\frac{Y}{N}\right)_{i t}=$ per capita gross domestic product (GDP, 2010 constant US \$) in country $i$ at time $t ; R_{i t}=$ rural population density (person ha ${ }^{-1}$ ) in country $i$ at time $t$, a proxy for scale of total forest use $;\left(\frac{L}{A}\right)_{i t}=$ the ratio of labor to total forest area in country $i$ at time $t ;\left(\frac{K}{A}\right)_{i t}=$ the ratio of capital to total forest area in country $i$ at time $t ; I_{i t}=$ the ratio of the value of exports plus imports to GDP (trade intensity) in country $i$ at time $t$; $\emptyset_{i t} \cong \emptyset_{0}+\emptyset_{1}\left(\frac{Y}{N}\right)_{i t}+\emptyset_{2}\left(\frac{L}{A}\right)_{i t}+\emptyset_{3}\left(\frac{K}{A}\right)_{i t}+\emptyset_{4}\left(\frac{L}{A}\right)_{i t}\left(\frac{K}{A}\right)_{i t}$, suggesting that the marginal effect of trade intensity on planted forest area depends on the level of other variables; $D_{8}$ to $D_{12}=$ dummies for different regions in the following order: South America, Asia, Africa, Europe, and North America; $\varepsilon_{i t}=$ a random error term that varies over country $i$ at time $t$. 
The dependent variable, planted forest area, conforms to the definition of planted forests by FAO (2015): (i) planted, seeded, or coppiced forests of native species; and (ii) plantations for timber or for the provision of services consisting of native or introduced species. Planted forest area is assumed to have a negative or positive relationship with rural population density $(R)$. Although a negative relationship signifies that there is less area available for forest expansion with increasing rural population, the positive relationship may suggest that land use intensification by smallholders may free-up land for tree planting, despite no change or even increases in rural population densities (Lambin and Meyfroidt 2011). It is expected that countries with a higher share of labor per unit of total forest area and more capital per unit of total forest area ( $L / A$, and $K / A$, respectively) can invest more in intensive forest management or new plantations, and therefore their signs should be positive. Trade intensity $(I)$, the measure of a country's comparative advantage in producing and trading a forest product (the larger the value of $I$, the greater is the comparative advantage), should have a positive effect on planted forest area (Rudel et al. 2005; Turner et al. 2006). A positive sign for income per capita $(Y / N)$ and a negative sign for its quadratic term, $(Y / N)^{2}$, would suggest an inverse-U-shaped relationship of planted forest area with per capita income, whereas the reverse would indicate a U-shaped relationship.

\section{Data}

Data used in estimating Eq. 1 were comprised of a balanced panel of observations for 96 countries in five different time points (1990, 2000, 2005, 2010, and 2015), giving a total of 480 observations. The dataset consists of only those countries that regularly report their data on planted forest area. The planted forest area and total forest area data came from the Food and Agricultural Organization's Global Forest Resource Assessment Report (Food and Agriculture Organization 2015). Income (gross domestic product, GDP), population, and labor force data were obtained from the World Bank (2018). Data on capital stock and trade intensity were obtained from the Penn World Table database (Feenstra et al. 2015). Table 2 presents the description and the summary statistics of the variables. Specifically, the data indicate that for four of the six of the model variables, the standard deviation was many times greater than the mean. This fact, along with the relatively small sample size, suggests that findings of a high level of statistical significance will be difficult, which we do consider as the results unfold.

\section{Estimating the econometric model of planted forest area}

We first estimated three different panel data model specifications, each representing different assumptions about the distribution of the error term shown in Eq. 1: pooled ordinary least square (OLS), fixed effects (FE) and random effects (RE). The pooled OLS model, by assumption, does not capture any cross-sectional, time-invariant unobservable differences among countries, and the error term is assumed homoscedastic across all spatial-temporal units of observations (although generalized heteroscedasticity of the error term in Eq. 1 can be introduced). The FE model captures the variation of the independent variables in time but explicitly recognizes potential cross-sectional, time-invariant differences in the level of the dependent variable by allowing each country to have a separate constant term but a common coefficient for each explanatory variable. The variance of the error term in Eq. 1, however, is assumed homoscedastic (although, in estimation, generalized 
heteroscedasticity can be introduced). Time-invariant variables cannot be incorporated in the FE model and variance is assumed to be constant across the cross-sectional units.

The RE model allows for cross-sectional (cross-country) variation in error variance but no time-invariant differences in the level of the dependent variable across countries. To partially relax the assumption of no time-invariant cross-sectional differences in the level of the dependent variable, following previous research suggesting that planted forest area changes vary systematically across regions (Payn et al. 2015), we included region-specific dummies (for South America, Asia, Oceania, Europe, and North America).

Each of these three model specifications was estimated using natural logarithmic transformations of the continuous variables, so these variables' estimated coefficients represent elasticity estimates. The models were estimated using Stata IC/14 using Normal, robust and clustered (by country) standard errors to control for the effects of heteroscedasticity in the model. Furthermore, acknowledging the possibility of nonstationarity of regression variables (for which, due to a paucity of time series observations per country, were not amenable to unit root tests), we estimated the model using the first-differences of the natural logarithms of the continuous variables, with robust standard errors to mitigate problems of omitted variables biases and potential spurious regression. The statistically most superior model was selected based on a pooling test and overall model goodness of fit.

Rejection of the null hypothesis in the pooling test (Table 3) suggested a better fit for the RE model compared to the OLS model. The analysis further revealed several statistically non-significant coefficients with unexpected signs found for FE model. Because the empirical fit proved better, we decided to proceed with the RE model with regional dummy variables. Although a FE-model is perceived as more suitable for country level analysis (Bell et al. 2019), our results suggest that there are some location-specific attributes, other variables, or data limitations that the FE model was unable to account for in our study context.

\section{Projecting global planted forest area under different SSPs}

The estimated parameters of Eq. 1 were used to project planted forest area by country to 2100 , under various scenarios of economic and demographic changes represented in various SSPs. In this study, we report the projected planted forest area only for three out of the five SSPs (SSP2, SSP3, and SSP5) because of the similarity of results for SSP1 and SSP5 and the similarity of results for SSP3 and SSP4.

The projection of total forest area was made for 152 countries under each SSP for which projected data on the explanatory variables were available. The available future data needed for projecting planted forest area were income per capita, $Y / N$, its squared term, $(Y / N)^{2}$, rural population per unit of forest area, $R$ (a proxy for rural population density), and labor per unit of total forest area, $L / A$. Data on future GDP $(Y)$ and population $(N)$ for each country in each SSP were obtained from the International Institute for Applied Systems Analysis (IIASA) projection database (IIASA 2018). The projected $L / A$ data were generated by forcing the $2015 \mathrm{~L} / \mathrm{A}$ value to grow at the same rate as the projected population in each SPP. Similarly, projected values for $R$ for each country in each SSP were estimated by dividing rural population (IIASA 2018) by rural land area (Jiang and O'Neill 2017) (detailed calculations available by request). The projected average values of $Y / N$, $R$, and $L / A$ for different geographical regions are shown in Figs. 2, 3 and 4. The projected trends on these variables for each region were generally similar to the respective trends for individual countries within each region (discussed further in results section), which largely determined projected trends of planted forest area across the SSPs. The quantitative 


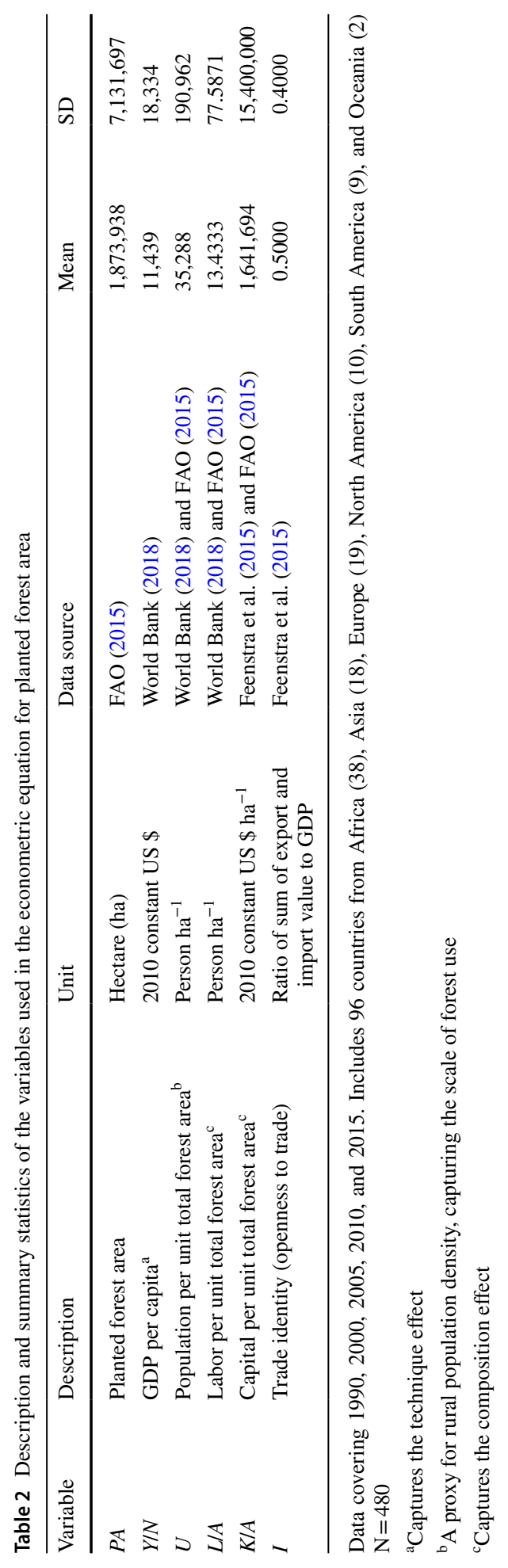


projections of the remaining explanatory variables for the SSPs were not available, so their effects on forest area were held constant when projecting planted forest area under each SSP.

\section{Results}

Table 3 summarizes the coefficients (which are interpreted as elasticities), standard errors, and the statistical significances of the estimated RE model specification (results for other specifications available by request). While the per capita income term (Y/N) was estimated to have a positive and significant relationship with planted forest area, its squared term $\left(Y / N^{2}\right)$ was negative and non-significant at traditional thresholds $(p$ value $=0.127)$. However, to avoid potential Type 2 errors, we decided to keep the $(Y / N)^{2}$ term in the model in projecting planted forest area. In addition, the independent variables in this final model were usually significant with the expected signs, indicating the merits of the model selected.

The relationship between planted forest area and $Y / N$ demonstrated near unitary elasticity, with a $1 \%$ increase in $Y / N$ being associated with a $1.07 \%$ increase in planted forest area. All other variables had their expected signs, although the signs on the coefficients of interaction variables and regional dummies were unknown beforehand. The estimated

Table 3 Estimated coefficients, standard errors, and significance levels of the random effects version of the Eq. 1 of global planted forest area

\begin{tabular}{lrll}
\hline Variables & Estimate $^{\mathrm{a}}$ & \multicolumn{1}{l}{ SE } & Significance \\
\hline Intercept & 17.8010 & 3.8730 & $* * *$ \\
$\mathrm{Y} / \mathrm{N}$ & 1.0734 & 0.5806 & $*$ \\
$\mathrm{Y} / \mathrm{N} 2$ & -0.0519 & 0.0340 & (Significant at 13\% level) \\
$\mathrm{U}$ & -1.3069 & 0.3646 & $* * *$ \\
$\mathrm{~L} / \mathrm{A}$ & 1.9764 & 0.4140 & $* * *$ \\
$\mathrm{~K} / \mathrm{A}$ & 0.0296 & 0.0908 & \\
L/A $*$ K/A & -0.4701 & 0.0128 & $* * *$ \\
$\mathrm{I}$ & 0.2057 & 0.2954 & \\
$\mathrm{I} *$ Y/N & -0.0538 & 0.0762 & \\
$\mathrm{I} *$ L/A & 0.1592 & 0.1180 & \\
I $*$ K/A & 0.0315 & 0.0597 & \\
I L/A $*$ K/A & -0.0213 & 0.0103 & $* *$ \\
SouthAmerica & -0.4110 & 1.4827 & \\
Asia & -0.4805 & 1.4319 & \\
Africa & -1.6366 & 1.3843 & $* * *$ \\
Europe & 0.2334 & 1.4094 & $*$ \\
NorthAmerica & -2.4846 & 1.4726 & $* * *$ \\
R ${ }^{2}$ (adjusted) & 0.2615 & & \\
Pooling test & 40.7900 & & $* * *$ \\
\hline
\end{tabular}

Numbers in parentheses are standard errors

$* * *$ Statistically significant at $1 \%, * *$ at $5 \%$, *at $10 \%$; see Table 2 for variable explanations

${ }^{\text {a }}$ The specified model was a $\log -\log$ model; therefore, the estimated coefficients are also of elasticity estimates 
coefficient of $R$ was negative and statistically significant, with an elastic relationship with planted forest area, suggesting that a $1 \%$ increase in rural population density would decrease planted forest area by $1.31 \%$. The $L / A$ coefficient demonstrated a positive and highly elastic and statistically significant relationship with planted forest area, indicating that a $1 \%$ increase in labor force per unit of forest area is associated with a $1.98 \%$ increase in planted forest area. The $K / A$ coefficient was not statistically significant, although it had the expected positive sign.

The interaction term of $L / A$ and $K / A$ was statistically significant and negative. The negative sign was contrary to expectation, since a positive sign was expected for both $L / A$ and $K / A$. However, the estimated coefficient was small $(-0.05)$, indicating that a $1 \%$ increase in both $L / A$ and $K / A$ is associated with a $0.05 \%$ decrease in planted forest area. Trade intensity (I) was not statistically significant, although its sign was positive, as expected.

Finally, the coefficient of the interaction term of $I, L / A$, and $K / A$ was statistically significant and negative. The negative relationship with planted forest area suggests that the degree of a country's comparative advantage in the trade of forest products in global markets depends on the interaction of labor per unit forest area and capital per unit of forest area. Stated differently, increasing trade openness is not helpful in expanding planted forest area when a country has a large labor force and a large capital stock per unit of forest area available.

\section{Projected global planted forest area}

For each SSP, the projected global planted forest area using the estimated model parameters showed increasing trends for the next three to four decades and declining trends thereafter. The projected planted forest area in each SSP over time is consistent with the estimated Eq. 1 (Table 3) and the projected trends for the explanatory variables (Figs. 2, 3, 4). Compared to initial planted areas totaling 293 Mha in 2015, SSP5 showed the largest increase by 2055 (to 334 Mha, a 14\% increase), followed by SSP2 (to 327 Mha or an 11\% increase). For SSP3, the projected increase in planted forest area was highest in 2045 (to 319 Mha, a rise of $9 \%$ from the 2015 level). By 2100, although SSP2 and SSP3 showed increases of only $2 \%$ and $3 \%$, respectively, SSP5 did not show any increase in global planted forest area, relative to the 2015 level (Fig. 1).

The estimated model indicates a positive impact of per capita income and labor per unit forest area but a negative impact of rural population density on planted forest area, the net effect on planted forest area depending on the magnitude of changes in those explanatory variables. For instance, the largest per capita income (Fig. 2a-f) growth, coupled with a lower population density (Fig. 3a-f) projected for most countries in SSP5, contributed to the largest global increase in planted forest area before 2055, although a lower rate of projected growth in labor per unit forest area (Fig. $4 \mathrm{a}-\mathrm{f}$ ) in this scenario dampened the projected net increase in planted forest area. By 2100, the higher magnitudes of growth in labor per unit forest area in SSP3 and in SSP2 compared to SSP5 led to lower declines in planted forest areas in these two scenarios compared to SSP5.

Projected trends in planted forest area varied substantially by world region, a result linked to their differing trajectories in explanatory variables. For instance, Africa showed the largest percentage increases in planted forest area in all SSPs, among all regions (Fig. 5a), resulting in increases by 2100 of $133 \%, 122 \%$, and $72 \%$ for SSP3, SSP2, and SSP5, respectively, compared to the observed 2015 level (16 Mha). While SSP2 and SSP3 showed almost linear trends in planted forest area growth in Africa, it declined after 2075 
for SSP5. The largest increase in planted forest area in Africa in SSP3 is consistent with the largest projected increase in labor force growth in this scenario, which more than doubles by 2100 compared to the 2015 level (Fig. 4a). However, lower income per capita (Fig. 2a) and higher rural population density (Fig. 3a) growth dampened the projected overall increase in planted forest area in SSP3 for Africa.

Asia showed contrasting trends in projected planted forest areas to 2100 (Fig. 5b), compared to its observed 2015 level. It increased through 2035 in all scenarios but then decreased in both SSP2 and SSP5, owing largely to higher rural population densities (Fig. 3b), coupled with a smaller labor force (Fig. 4b) projected in these scenarios in the later projection years, relative to SSP3. For instance, projected planted forest area in SSP2 and SSP5 declined by $14.9 \%$ and $29.1 \%$, respectively, but SSP3 showed a slight increase (4.3\%) by 2100, compared to the observed 2015 area of planted forests.

For Europe, planted forest area in 2100 was projected to decline in SSP2 and SSP3 by $4.5 \%$ and $18.1 \%$, respectively, but was projected to increase in SSP5 by $6.3 \%$, relative to the 2015 level, although the trends were increasing until 2070 for SSP5 and until 2055 for SSP2 (Fig. 5c). The largest projected decline in planted forest area in Europe (SSP3) can be linked to the slowest growth in per capita income (Fig. 2c) and labor per unit forest area (Fig. 4c) compared to other world regions, although the low rural population density (Fig. 3c) in this scenario helped increase Europe's planted forest area. The largest projected increase in planted forest area in Europe (SSP5) can be linked to relatively higher growth in per capita income (Fig. 2c) and labor per unit forest area (Fig. 4c), although projected higher growth in rural population density (mostly before 2075) helped to decrease planted forest area development in this scenario (Fig. 3c).

Unlike other regions, North America showed the largest variation in projected planted forest area across SSPs, showing a decline of $16.7 \%$ in SSP3, an increase of $19.3 \%$ in SSP2, and an increase of $49.9 \%$ in SSP5, by 2100, compared to its 2015 area of planted forests (Fig. 5d). The decline in planted forest area in SSP3 is associated with the lowest growth in average per capita income (Fig. 2d) coupled with the highest growth in rural population density (Fig. 3d). This planted forest area decline was despite a higher projected labor force in this scenario (Fig. 4d), which, because of its positive relationship with planted forest area, would tend to put a damper on losses. Similarly, the largest projected increase in planted forest area, found in SSP5, is explained by the higher projected income per capita growth and lower projected growth in rural population density, despite lower projected growth in labor per unit of forest area (Figs. 2d, 3d, $4 d)$.

The prospective planted forest area futures for Oceania (Fig. 5e) are similar to those projected for North America, showing large variation in projected planted forest area changes across the SSPs, with SSP2, SSP3, and SSP5 showing a 26.7\% increase, a $6.0 \%$ decline, and a 53.3\% increase, respectively, by 2100, compared to 2015 areas. Similar to North America, the projected planted forest area for Oceania can also be attributed to projected growth in each of income per capita (Fig. 2e), rural population density (Fig. 3e), and labor per unit of forest area (Fig. 4e).

Finally, the projected planted forest area outlook for South America (Fig. 5f) varied from a decline of $23.2 \%$ in SSP5 to an increase of $34.2 \%$ in SSP3 by 2100 , compared to its 2015 level, with SSP2 showing an increase of just 1.3\%. The projected decline in planted forest area in South America in SSP5 is linked to low growth in labor per unit forest area (Fig. 4f), although the projected highest growth in per capita income (Fig. 2f) and the lowest rural population density (Fig. 3f) tended to increase planted forest area in this scenario. 


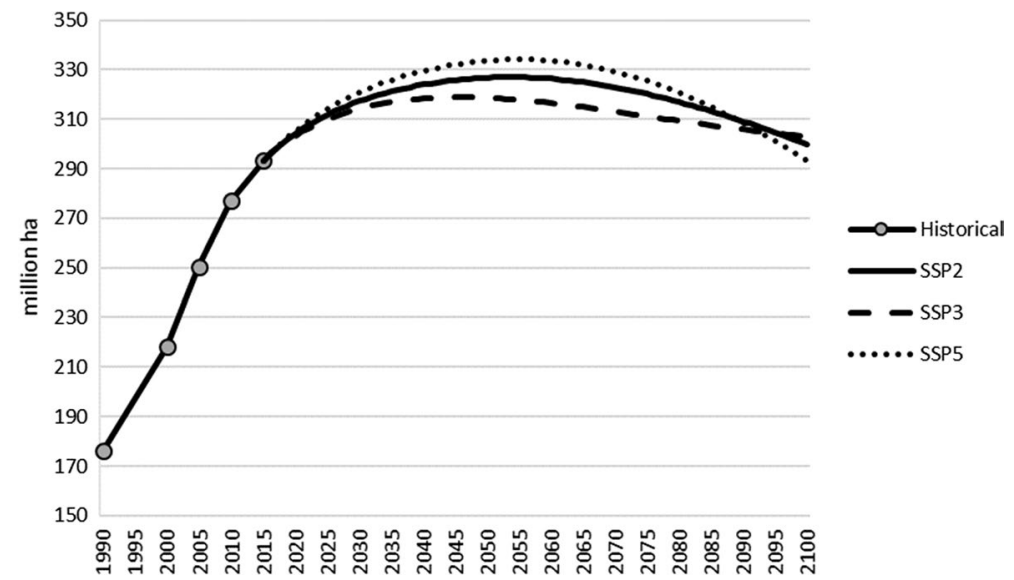

Fig. 1 Projected global planted forest area (million ha) under the shared socio-economic pathways (SSPs) 2, 3, and 5, 2015-2100. Projected explanatory variables driving the total forest area projection include per capita income, per capita income squared, labor per forest area, and rural population density. The results represent the sum of projections for 152 countries, including 45 countries in Africa, 39 in Asia, 36 in Europe, 14 in North America, 7 in Oceania, and 11 in South America

The largest increase in planted forest area in South America, under SSP3, is mainly attributable to the projected high labor per unit of forest area compared to SSP2 and SSP5.

\section{Discussion and conclusions}

Recently published research modeled planted forest area change as linear function of income per capita change (Korhonen et al. 2014; Nepal et al. 2019c), and our study bolsters that modeling approach. In addition, our study offers modest evidence of a negative quadratic per capita income term at a $13 \%$ significance level, which is reasonable given the quite sparse and variable planted forest panel data available. This quadratic term does project that planted forest area changes may begin to decline at higher per capita income levels. This outcome is consistent with the view that rising incomes are associated with progressively greater attention to the adverse environmental or social impacts of planted forests (Malkamäki et al. 2018). Thus, the nature of the relationship between economic growth and sustainability of planted forest area growth merit additional scrutiny, focused on understanding the role of planted forests in achieving sustainability goals (SDG 12, UN 2017).

In addition to our finding that planted forest increases may be tempered by higher income levels, this article provides insights into the potential future of planted forest area under varying economic and demographic trajectories envisioned in different SSPs. Our results show that different SSPs are likely to result in different outlooks for, and distributions of, planted forest area among the continents. SSP5, which anticipates resource intensive production and consumption, brings with it a prediction of the greatest increase in areas of planted forests in Africa, Europe, North America and Oceania; in Asia and South America, in contrast, the planted forest growth is the most modest. Respectively, the planted forest area in Asia and South America grows the most under SSP3, which emphasizes "regional rivalry". 


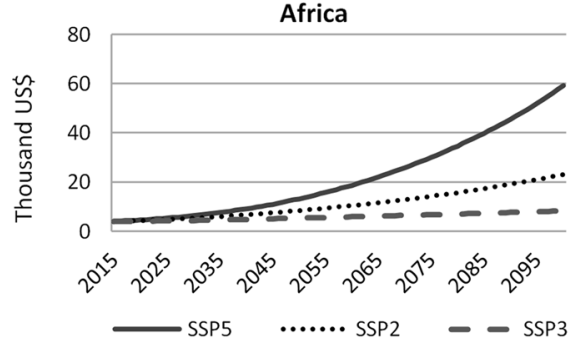

(a)

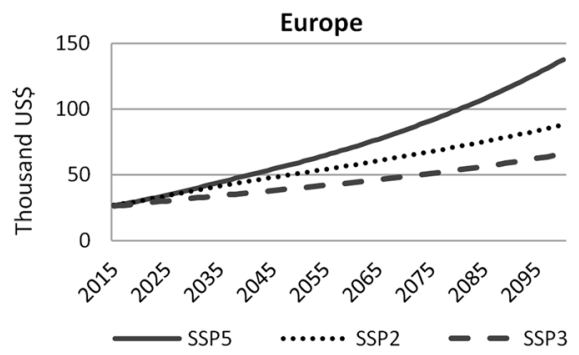

(c)

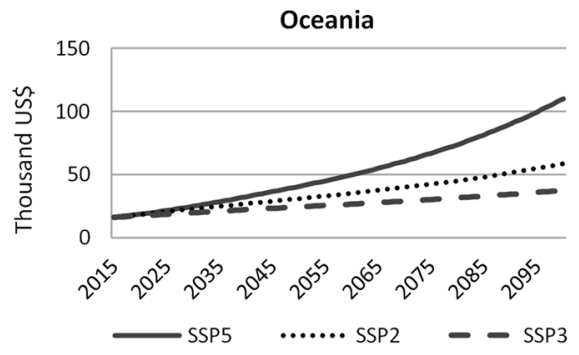

(e)

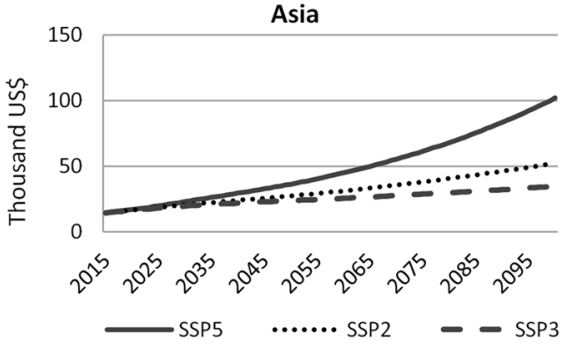

(b)

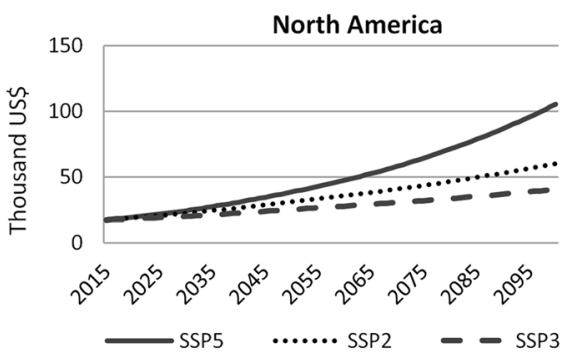

(d)

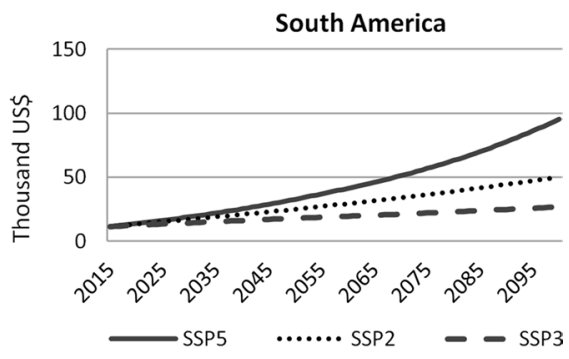

(f)

Fig. 2 Projected average per capita gross domestic product (2010 constant US\$) for major world regions under shared socio-economic pathways (SSPs) 2, 3, and 5, 2015-2100. Note: includes 50 countries in Africa (a), 47 in Asia (b), 37 in Europe (c), 22 in North America (d), 11 in Oceania (e), and 13 in South America (f). Data source: IIASA (2018)

The sustainability consequences of these projected planted forest area changes depend on multiple interlinked drivers that we could not capture with the data and statistics available for our modeling. For example, based on our analyses, we cannot conclude whether planted forests will substitute for natural forests or even lead to losses of other ecologically prestigious habitats. Nonetheless, we can suggest some risks related to the different SSPs and planted forests. In cases where we anticipate high population growth and consumption growth without a stringent regulation (SSP3), Asia or South America might be particularly under at risk of unsustainable forest plantation levels. In the other regions, greater planted forest development is found with SPP5, which could be attributable to the highly resourceintensive and fossil-fuel-dependent future (O'Neill et al. 2017), coupled with a positive assumption of high productivity growth and diffusion of best practices in planted forest management (Daigneault et al. 2019). 


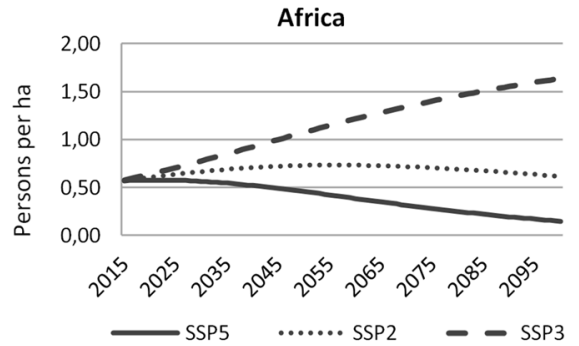

(a)

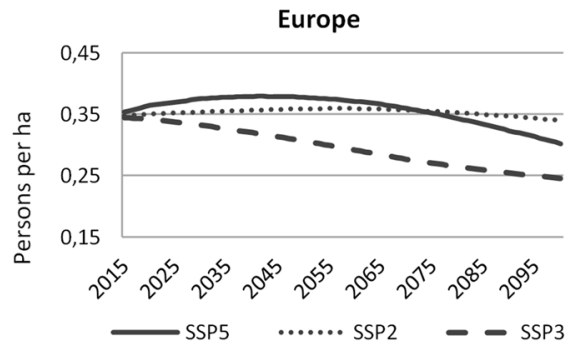

(c)

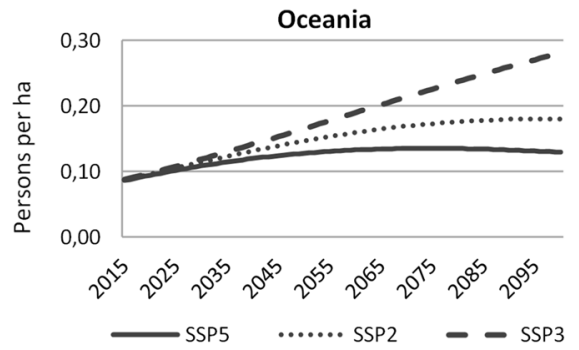

(e)

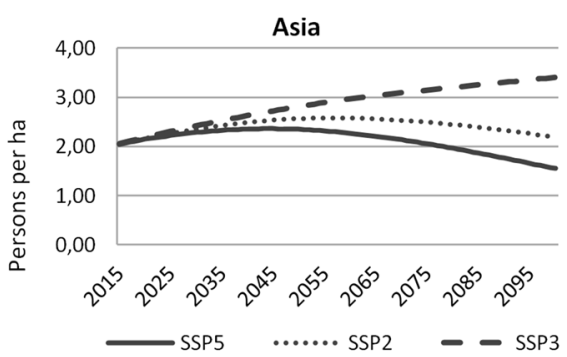

(b)

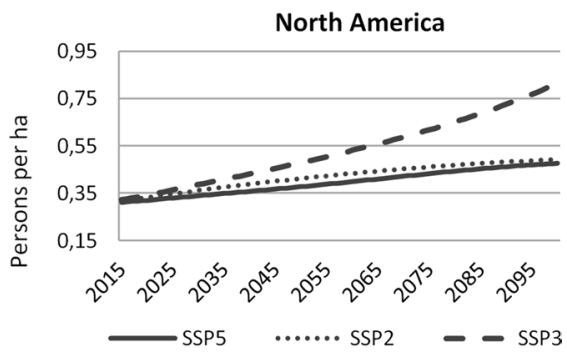

(d)

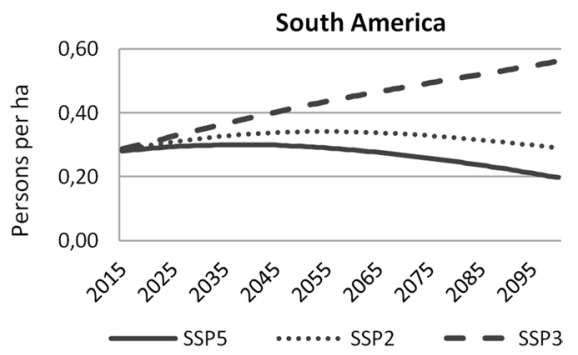

(f)

Fig. 3 Projected rural population density (persons per ha) for major world regions under shared socio-economic pathways (SSPs) 2, 3, and 5, 2015-2100. Note: includes 48 countries in Africa (a), 46 in Asia (b), 36 in Europe (c), 17 in North America (d), 9 in Oceania (e), and 12 in South America (f). Data sources: World Bank (2018) and Jiang and O'Neill (2017). Rural land area was assumed to change in the future in proportion to the projected trends in rural population

We compared our projections with our previous planted forest area outlook reported by Nepal et al. (2019c), which provided outlooks of planted forest area development through 2070 for each SSP and which were linearly driven by GDP per capita and roundwood production quantities projected in each country in each SSP. Our model projects smaller increases in global planted area than the increases reported by Nepal et al. (2019c) for the same scenario. For instance, while we projected a $10 \%$ increase in global planted forest area by 2070 relative to 2015 level for SSP2 ("the middle road"), Nepal et al. (2019c) projected a $46 \%$ increase for the same scenario during the same period. The differences in two model projections are due to evident differences in model specification between mostly 


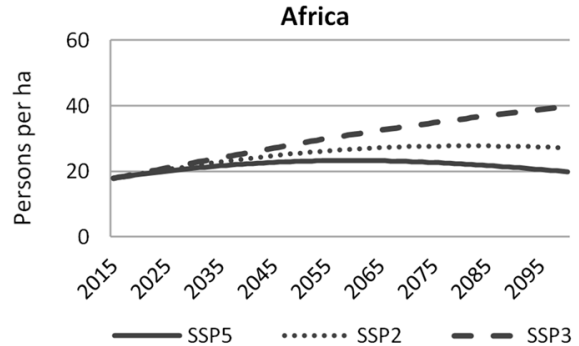

(a)

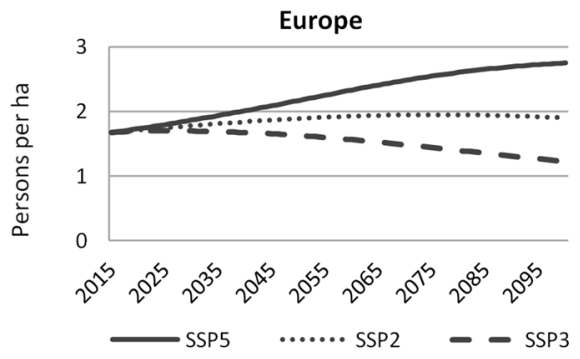

(c)

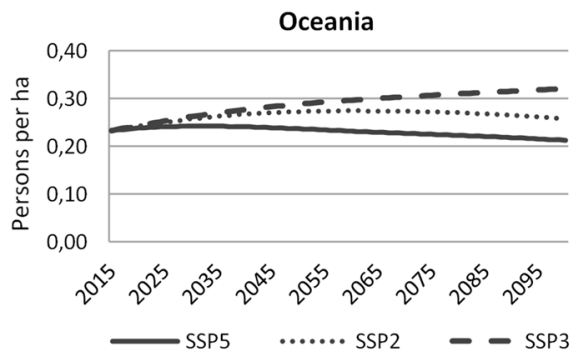

(e)

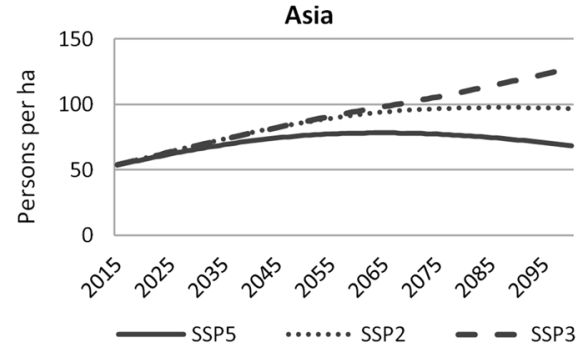

(b)

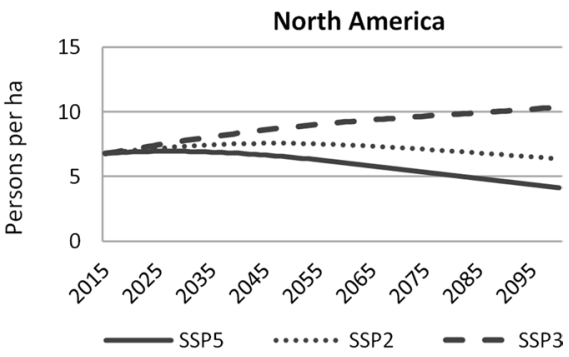

(d)

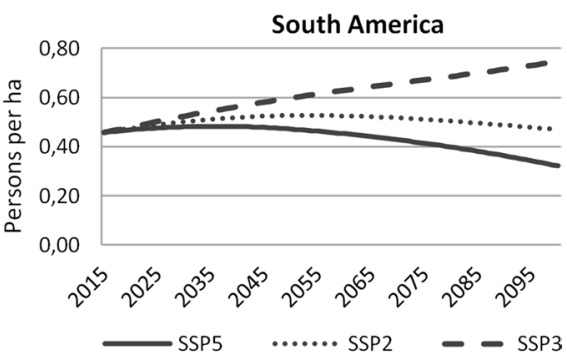

(f)

Fig. 4 Projected average labor per forest area (persons per ha) for major world regions under shared socioeconomic pathways (SSPs) 2, 3, and 5, 2015-2100. Note: includes 48 countries in Africa (a), 46 in Asia (b), 36 in Europe (c), 17 in North America (d), 9 in Oceania (e), and 12 in South America (f). Data sources: World Bank (2018) and FAO (2015). The base year labor per forest area was assumed to follow the population growth trends projected in the various shared socio-economic pathways

linear versus quadratic independent variable formulations and the more extensive planted forest area drivers included in our study.

Our model projects larger increases in planted forests for Africa (increasing by $99 \%$ from 2015 to 2070), North America (+20\%) and Oceania (+28\%) under SSP2, compared to Nepal et al. (2019c), which showed increases in those regions by $65 \%, 16 \%$, and $14 \%$, respectively, during the same time span and scenario. More differences in projections were observed for Asia and Europe, where our model showed almost no growth in planted forest area, and also for South America, where our model showed a 13\% increase in SSP2, by 2070, relative to 2015 levels. In contrast, Nepal et al. (2019c) showed increases of $46 \%$, $23 \%$, and $38 \%$ in those regions, respectively, during the same period and same scenario. 


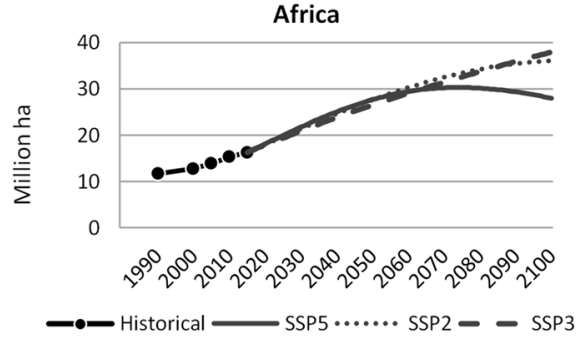

(a)

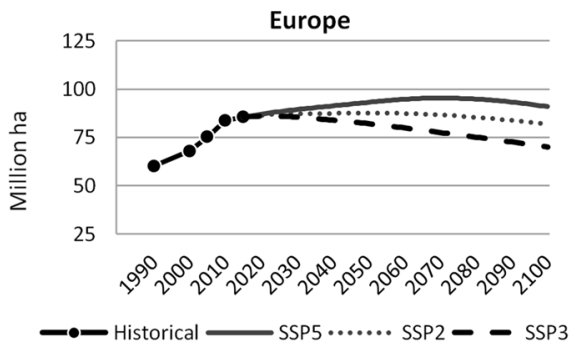

(c)

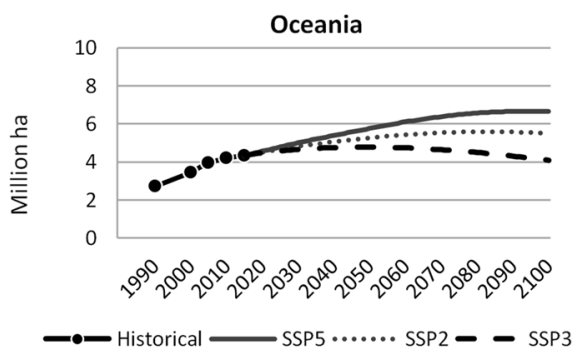

(e)

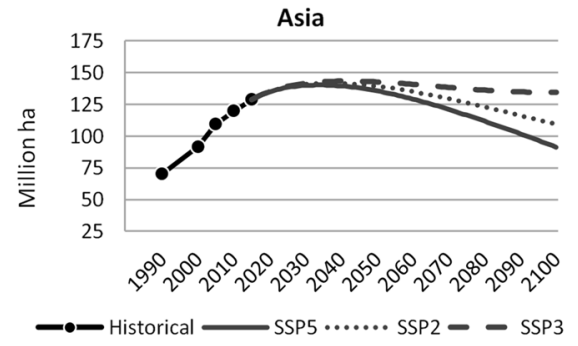

(b)

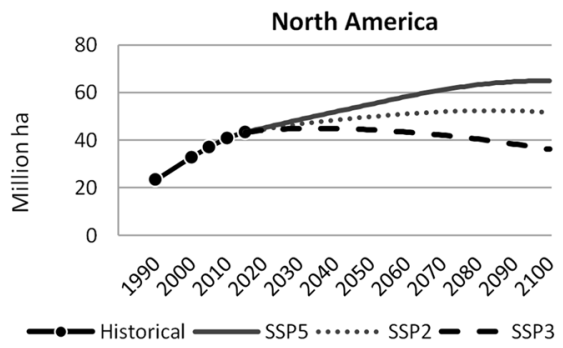

(d)

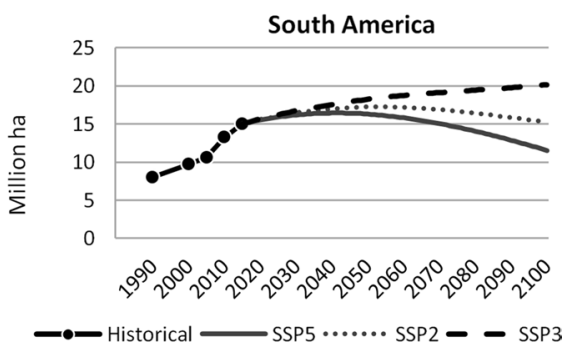

(f)

Fig. 5 Projected planted forest area (million ha) for major world regions under shared socio-economic pathways (SSPs) 2, 3, and 5, 2015-2100. Projected explanatory variables driving planted forest area projection include per capita income, its squared term, labor per forest area, and rural population density. The results represent 45 countries in Africa (a), 39 in Asia (b), 36 in Europe (c), 14 in North America (d), 7 in Oceania (e), and 11 in South America (f)

Both of our approaches here and in research reported in Nepal et al. (2019c) still project less future plantation area than the largely linear projections based on sigmoid projections of past data (e.g., Carle and Holmgren (2008), d'Annunzio et al. (2015)). Our study also complements the study by Daigneault et al. (2019) by associating the SSPs narratives created for forest sector with the quantitative sector scenarios that are inspired by SSPs imagining more alternative socio-economic pathways (O'Neill et al. 2017).

It bears stating that projections to the next century of planted forests are made under the assumption that model parameters do not change. Hence, broad conclusions about absolute levels of planted forests, given assumed future incomes per capita, should be made with caution. Such caution would also carry over to evaluation of the effects of 
policies, including those intended to counteract potential reductions (assuming a negative sign on quadratic income per capita) in planting at higher income levels. This study provides potentially valuable background information for private forest investors and for public policy makers. The earlier years of our projections are well within the investment planning horizons for investors and policy makers considering planted forests in the context of timber markets, country competitiveness, and environmental benefits such as carbon storage.

Our robust analyses and close linkage to SSPs provide a relatively narrow range of total planted forest projections of between 319 and 334 Mha by 2100, depending on the SSP pathway. This projected amount is still less than the sum of individual country or global expectations stated in the last few years, as reviewed in our introduction (e.g., IUCN 2015; WWF 2012). For example, Bastin et al. (2019) estimated global technical potential for woodlot creation to meet global demand for forest product markets and for climate change mitigation to be as high as 900 million ha. The World Economic Forum (WEF 2020) goal of 1 trillion trees (1t.org 2020) would represent roughly 1 billion ha of forests at 1000 trees per ha, or three times as much area as we project. Furthermore, at an establishment costs of about $\$ 1500$ per ha without overhead costs (Cubbage et al. 2007, 2020), an additional billion ha of forests would require about $\$ 1.5$ trillion dollars of new funds, an amount many times greater than all prior global forest planting investments in total. The differences between our projected planted forest area and upper level global aspirations indicate that historical barriers to planted forest expansion would need to be addressed, including land availability, complex land tenure considerations, trade-offs with natural forests and associated environmental impacts, and identification of novel sources of funding. Issues such as these have prompted criticism of the 1 trillion goal as well (e.g., Calma 2020), so our econometric analyses of historical trends suggest that lesser levels of planted forests are more plausible, providing a useful reality check to policy goals. Projecting futures inherently involves a significant level of uncertainty, and projecting planted forests at a global scale requires a balance between a theoretical structure that is general enough to cover the variability of economic situations in different countries and the availability of international data (Turner et al. 2006).

Our analysis indicates that projecting the continuation of historical socio-economic trends under SSP2, planted forest areas are apt to increase at lower rates than found in previous studies. Of course, this analysis does not provide information on the planted forest area and natural forest area interplay, or possible adverse impacts of planted forest area expansion on, e.g., local communities (Malkamäki et al. 2018), which will largely define whether the planted forest expansion is sustainable. Nonetheless, the merits of planted forests for fiber and especially for climate change reduction in tropical countries, such as suggested by Busch et al. (2019), should be considered by policy makers when they consider policies such as payments for net carbon emissions reductions, or indeed for many other benefits of planted forests such as water quality, biodiversity, or recreational values. These broad benefits would augur for concerted global efforts to maintain higher planted forest increases than we projected here with this more comprehensive model than employed in previous research.

Our findings here of somewhat lesser projected areas of planted forests in the future do have significant policy implications for both advocates and critics of plantations. Our findings suggest that wood production from planted forests will stabilize, unless higher productivity and growth rates offset more modest area expansions (see discussion in Daigneault et al. (2019) about anticipated effects of SSPs on the planted forest management). Our findings also indicate that in order to achieve the desired effects in reducing climate change, 
greater policy interventions will be required, such as those supporting a higher price for carbon storage (e.g., Busch et al. 2019). For instance, based on the estimated marginal abatement cost curve for 90 tropical and subtropical countries, Busch et al. (2019) found that carbon prices of USD 20 and 50 per ton would incentivize tropical land users to increase reforestation, 2020-2050, by $8 \%$ and $22 \%$, respectively, relative to their projected reforestation under their business-as-usual scenario with a zero carbon price.

On the other hand, the lower projected area estimates suggest that fears of adverse effects from planted forests are not as likely given the trends we projected here. Regardless, more systematic studies on the diverse socio-economic drivers and projected trends in planted forests, and their interlinkages, e.g. with a carbon price (Busch et al. 2019), carbon storage (Pihlainen et al. 2014; Assmuth and Tahvonen 2018), biodiversity policies, or tree species selection (Potter et al. 2017a, b, Matthies and Valsta 2016), at regional and global levels, could improve information and discussion and better guide private investors and public decision makers.

Acknowledgements Open access funding provided by University of Helsinki including Helsinki University Central Hospital. Funding for this research was provided by the USDA Forest Service agreements 14-JV-11330143-101 and 19-JV-11330143-023 for the Resources Planning Act (RPA) Assessment and the National Sustainability Assessment programs. Dr. Korhonen thanks the Academy of Finland for financial support (307480). We thank Dr. Olli-Pekka Kuusela for his comments on the previous draft and two previous reviewers for their reviews.

Open Access This article is licensed under a Creative Commons Attribution 4.0 International License, which permits use, sharing, adaptation, distribution and reproduction in any medium or format, as long as you give appropriate credit to the original author(s) and the source, provide a link to the Creative Commons licence, and indicate if changes were made. The images or other third party material in this article are included in the article's Creative Commons licence, unless indicated otherwise in a credit line to the material. If material is not included in the article's Creative Commons licence and your intended use is not permitted by statutory regulation or exceeds the permitted use, you will need to obtain permission directly from the copyright holder. To view a copy of this licence, visit http://creativecommons.org/licenses/by/4.0/.

\section{References}

1t.org (2020) A platform for the trillion tree community. Initiative by WEF. https://www.1t.org/. Accessed 19 Apr 2020

Antweiler W, Copeland BR, Taylor MS (2001) Is free trade good for the environment? Am Econ Rev 91(4):877-908. https://doi.org/10.1257/aer.91.4.877

Assmuth A, Tahvonen O (2018) Optimal carbon storage in even- and uneven-aged forestry. For Policy Econ 87:93-100. https://doi.org/10.1016/j.forpol.2017.09.004

Bastin JF, Finegold Y, Garcia C, Mollicone D, Rezende M, Routh D, Zohner CM, Crowther TW (2019) The global tree restoration potential. Science 365(6448):76-79. https://doi.org/10.1126/science.aax0848

Bell A, Fairbrother M, Jones K (2019) Fixed and random effects models: making an informed choice. Qual Quant 53(2):1051-1074. https://doi.org/10.1007/s11135-018-0802-X

Bonnefoi B, Buongiorno J (1990) Comparative advantage of countries in forest products trade. For Ecol Manag 36:1-17

Busch J, Engelmann J, Cook-Patton SC, Griscom BW, Kroeger T, Possingham H, Shyamsundar P (2019) Potential for low-cost carbon dioxide removal through tropical reforestation. Nat Clim Change 9:463466. https://doi.org/10.1038/s41558-019-0485-X

Calma J (2020) Planting 1 trillion trees might not actually be a good idea. The Verge. https://www.theve rge.com/2020/1/31/21115862/davos-1-trillion-trees-controversy-world-economic-forum-campaign. Accessed 19 Apr 2020

Carle J, Holmgren P (2008) Wood from planted forests: a global outlook 2005-2030. For Prod J 58:6-18 
Cole MA, Elliott RJR (2003) Determining the trade-environment composition effect: the role of capital, labor and environmental regulations. J Environ Econ Manag 46(3):363-383. https://doi.org/10.1016/ S0095-0696(03)00021-4

Cubbage F, Mac Donagh P, Sawinski J, Rubilar R, Donoso P, Ferreira A, Hoeflich V, Olmos VM, Ferreira G, Balmelli G, Siry J, Báez MN, Alvarez J (2007) Timber investment returns for selected plantations and native forests in South America and the southern United States. New For 33:237-255. https://doi. org/10.1007/s11056-006-9025-4

Cubbage F, Kanieski B, Rubilar R, Bussoni A, Olmos VM, Balmelli G, Donagh P Mac, Lord R, Hernández C, Zhang P, Huang J, Korhonen J, Yao R, Hall P, Del La Torre R, Diaz-Balteiro L, Carrero O, Monges E, Thu HTT, Frey G, Howard M, Chavet M, Mochan S, Hoeflich VA, Chudy R, Maass D, Chizmar S, Abt R (2020) Global timber investments, 2005-2017. For Policy Econ 112:102082. https://doi. org/10.1016/j.forpol.2019.102082

d'Annunzio R, Sandker M, Finegold Y, Min Z (2015) Projecting global forest area towards 2030. For Ecol Manag 352:124-133

Daigneault AJ, Johnston C, Korosuo A, Baker JS, Forsell N, Prestemon JP, Abt RC (2019) Developing detailed Shared Socioeconomic Pathway (SSP) narratives for the global forest sector. J For Econ 34(12):7-45. https://doi.org/10.1561/112.00000441

FAO/FRA (2015) Forest Resources Assessment 2015: terms and definitions. In: Forest Resources Assessment. https://doi.org/10.1002/2014GB005021

Feenstra RC, Inklaar R, Timmer MP (2015) The next generation of the Penn World Table: online appendix. Am Econ Rev 105:3150-3182. https://doi.org/10.1257/aer.20130954

Food and Agriculture Organization (2015) Global Forest Resources Assessment 2015. Desk reference. In: Desk Reference. https://doi.org/10.1002/2014GB005021

IIASA (2018) SSP Database, International Institute for Applied Systems Analysis, Vienna, Austria. https:// tntcat.iiasa.ac.at/SspDb. Accessed 3 June 2018

IPCC (Intergovernmental Panel of Climate Change) (2019) Climate change and land summary report. https://ipcc.ch/report/srccl. Accessed 26 Aug 2019

IUCN (International Union for the Conservation of Nature) (2015) Forest landscape restoration. https:// www.iucn.org/about/work/programmes/forest/fp_our_work/fp_our_work_thematic/fp_our_work_ flr/. Accessed 4 Sept 2019

Jiang L, O’Neill BC (2017) Global urbanization projections for the Shared Socioeconomic Pathways. Glob Environ Change 42:193-199

King M, Altdorff D, Li P, Galagedara L, Holden J, Unc A (2018) Northward shift of the agricultural climate zone under 21st-century global climate change. Sci Rep 8:7904. https://doi.org/10.1038/s41598-01826321-8

Lambin EF, Meyfroidt P (2011) Global land use change, economic globalization, and the looming land scarcity. Proc Natl Acad Sci USA 108(9):3465-3472. https://doi.org/10.1073/pnas.1100480108

Malkamäki A, D’Amato D, Hogarth NJ, Kanninen M, Pirard R, Toppinen A, Zhou W (2018) A systematic review of the socio-economic impacts of large-scale tree plantations, worldwide. Glob Environ Change 53:90-103. https://doi.org/10.1016/j.gloenvcha.2018.09.001

Matthies BD, Valsta LT (2016) Optimal forest species mixture with carbon storage and albedo effect for climate change mitigation. Ecol Econ 126:95-105. https://doi.org/10.1016/j.ecolecon.2016.01.004

Nepal P, Korhonen J, Prestemon J, Cubbage F (2019a) Global forest area outlook suggested by the updated Environmental Kuznets Curve model under varying futures of economic and demographic changes. Forests 10(5):387. https://doi.org/10.3390/f10050387

Nepal P, Abt K, Skog K, Prestemon P, Abt R (2019b) Projected market competition for wood biomass between traditional products and energy: a simulated interaction of US regional, national, and global forest product markets. For Sci 65(1):14-26. https://doi.org/10.1093/forsci/fxy031

Nepal P, Korhonen J, Prestemon P, Cubbage FW (2019c) Projecting global planted forest area developments and the associated impacts on global forest product markets. J Environ Manag 240:421-430. https://doi.org/10.1016/j.jenvman.2019.03.126

O’Neill B, Kriegler E, Riahi KL, Hallegatte TR, Ritu M, van Vuuren DP (2014) A new scenario framework for climate change research: the concept of shared socioeconomic pathways. Clim Change 122:387-400. https://doi.org/10.1007/s10584-013-0905-2

O’Neill BC, Kriegler E, Ebi KL, Kemp-Benedict E, Riahi K, Rothman DS, van Ruijven BJ, van Vuuren DP, Birkmann J, Kok K, Levy M, Solecki W (2017) The roads ahead: narratives for shared socioeconomic pathways describing world futures in the 21st century. Glob Environ Change 42:169-180. https://doi.org/10.1016/j.gloenvcha.2015.01.004 
Payn T, Carnus J, Freer-smith P, Kimberley M, Kollert W, Liu S, Orazio C, Rodriguez L, Neves L, Wingfield MJ (2015) Changes in planted forests and future global implications. For Ecol Manag 352:57-67. https://doi.org/10.1016/j.foreco.2015.06.021

Pihlainen S, Tahvonen O, Niinimäki S (2014) The economics of timber and bioenergy production and carbon storage in Scots pine stands. Can J For Res 44(9):1091-1102. https://doi.org/10.1139/ cjfr-2013-0475

Popkin G (2019) How much can forests fight climate change? Nature 565:280-282. https://doi. org/10.1038/d41586-019-00122-z

Potter KM, Crane BS, Hargrove WW (2017a) A United States national prioritization framework for tree species vulnerability to climate change. New For 48:275-300. https://doi.org/10.1007/s1105 6-017-9569-5

Potter KM, Jetton RM, Bower A, Jacobs DF, Man G, Hipkins VD, Westwood M (2017b) Banking on the future: progress, challenges and opportunities for the genetic conservation of forest trees. New For 48:153-180. https://doi.org/10.1007/s11056-017-9582-8

Rudel TK, Coomes OT, Moran E, Achard F, Angelsen A, Xu J, Lambin E (2005) Forest transitions: towards a global understanding of land use change. Glob Environ Change 15:23-31. https://doi. org/10.1016/j.gloenvcha.2004.11.001

Sloan S, Sayer JA (2015) Forest Resources Assessment of 2015 shows positive global trends but forest loss and degradation persist in poor tropical countries. For Ecol Manag 352:134-145. https://doi. org/10.1016/j.foreco.2015.06.013

Turner JA, Buongiorno J, Zhu S (2006) An economic model of international wood supply, forest stock and forest area change. Scand J For Res 21:73-86. https://doi.org/10.1080/02827580500478506

United Nations (UN) (2017) Goal 12: responsible consumption and production. https://www.un.org/susta inabledevelopment/sustainable-consumption-production/

United Nations (UN) Climate Summit (2014) UN Climate Summit. New York declaration on forests. UN Headquarters, New York, NY

WEF (2020) One Trillion Trees. World Economic Forum, 2020. https://www.weforum.org/agenda/2020/01/onetrillion-trees-world-economic-forum-launches-plan-to-help-nature-and-the-climate/. Accessed 19 Apr 2020

World Bank (2018) World Bank Open Data. https://data.worldbank.org/. Accessed 18 Mar 2018

WWF (2012) Living forests report. https://wwf.panda.org/our_work/forests/forest_publications_news_and_ reports/living_forests_report/. Accessed 19 Apr 2020

Zhang X, Cai X (2011) Climate change impacts on global agricultural land availability. Environ Res Lett 6:014014. https://doi.org/10.1088/1748-9326/6/1/014014

Publisher's Note Springer Nature remains neutral with regard to jurisdictional claims in published maps and institutional affiliations.

\title{
Affiliations
}

\section{Jaana Korhonen $^{1}$ (D) Prakash Nepal ${ }^{2}$. Jeffrey P. Prestemon ${ }^{3} \cdot$ Frederick W. Cubbage $^{4}$}

\author{
Prakash Nepal \\ pnepal@ncsu.edu \\ Jeffrey P. Prestemon \\ jeff.prestemon@usda.gov \\ Frederick W. Cubbage \\ cubbage@ncsu.edu
}

1 Department of Forest Sciences, University of Helsinki, Latokartanonkaari 7, P.O. Box 27, 00014 Helsinki, Finland

2 Forest Products Laboratory, USDA Forest Service, One Gifford Pinchot Drive, Madison, WI 53726, USA

3 Forestry Sciences Laboratory, USDA Forest Service, Southern Research Station, 3041 E. Cornwallis Road, Research Triangle Park, NC 27709, USA

4 Department of Forestry and Environmental Resources, North Carolina State University, 2820 Faucette Dr., Campus Box 8001, Raleigh, NC 27695, USA 